\title{
Green synthesis of Novel Schiff bases derived from 2, 6 diamino pyridine - Characterization and Biological activity
}

\author{
Devika Bhai. ${ }^{1}$, C.R Girija ${ }^{2^{*}}$, Ramakrishna Reddy. $\mathrm{K}^{3}$ \\ ${ }^{1}$ Department of Chemistry, The Oxford College of Science, H.S.R Layout Bangalore, India \\ devikabhai@gmail.com \\ ${ }^{2}$ Department of Chemistry, SSMRV Degree College, Jayanagar $4^{\text {th }} \mathrm{T}$ Block, Bangalore, India \\ girijashivakumar@gmail.com* \\ ${ }^{3}$ Department of Chemistry, Government Science College, Nrupatunga Road, Bangalore, India \\ rkrchem@gmail.com
}

\section{ABSTRACT:}

Present work produces an excellent green route for the synthesis of Schiff bases derived from 2, 6 diamino pyridine, by using lemon juice as the catalyst. This method is experimentally simple, quick, clean and high yielding. Purity and yield of the reaction is increased by using lemon juice there by avoided the traditional dehydrating agents like glacial acetic acid. This method was successfully extended for the synthesis of different Schiff bases derived from 2,6 diamino pyridine like N,N'-bis(2-hydroxy-1-napthalene)-2,6-pyridiamine, N,N'-bis(2-methoxy-1-napthalene)-2,6-pyridiamine and N,N'-bis (naphthalene)- 2,6-pyridiamine. These compounds were prepared by using catalytic amount of lemon juice, and found more economical, safe, neat and eco friendly than using other commercially available dehydrating agents.

The synthesized compounds were characterized by FT-IR, 1HNMR spectroscopy, CHN analysis and mass. Compounds are screened for their antifungal activity against Aspergillusniger and M.fufur while antibacterial activity was checked against E.coli, Klebsiella, Bacillus cereus and Staphylococcus aureus. Hydroxyl derivative of the compound was showing significant anti bacterial activity against all selected bacteria. Klebsiella was showing a considerable inhibition compared to standard Tetracycline.

Key words: Green synthesis; Schiff bases and Anti microbial activity

\section{Council for Innovative Research}

Peer Review Research Publishing System

Journal: Journal of Advances in Chemistry

Vol. 10 , No. 5

editorjaconline@gmail.com

www.cirjac.com 


\section{Introduction:}

The search for new antibacterial agents to treat the bacterial infection has become an unavoidable area of scientific research due to the increasing incidence of multi resistant bacterial infections in the community as well as the development of bacterial resistance to available antibiotics. Schiff bases, a condensed product of aromatic amine and aldehydes have been known to posses wide range of applications like anti bacterial anti fungal, anti tumor, analgesic, anti inflammatory, anti toxic ,anti HIV, anti cancer as well as other biological activities [1]. It is been discovered that the specific $\mathrm{C}=\mathrm{N}$ bond in Schiff bases are the most crucial for these biological activities. Therefore poly cyclic Schiff bases derived from 2,6 diamino pyridine, which contains methoxy, and hydroxyl substituent have been preferentially synthesized through green route and compared the anti microbial activity with a least substituted derivative of the same.

\section{Importance of acid in the Schiff base synthesis}

The acid/base catalysis or heating is preferred for the synthesis of Schiff bases as their reactions are mostly reversible. The dehydration step during formation of Schiff base is the rate determining step and the reaction is catalyzed by acid. High concentration of acid is not needed due to basic due to basic character of amine [2].

Therefore low acidic $\mathrm{pH}$ are quite good for the formation of Schiff base. The usual methodologies like use of acid catalysts akin to Lewis acids or other commercially available acids reported to be having some disadvantages such as prolonged reaction time, the high reaction temperatures, an excess of costly dehydrating reagents/catalysts, moisture sensitive catalysts, and special apparatus, etc [2]. In the present work we have synthesized Schiff bases of substituted napthaldehyde and aromatic amines by employing Lemon juice as green catalyst.

Extract of Citrus limonium species of lemon is been used as natural catalyst for synthesis of Schiff bases. The main ingredients of lemon juice are moisture (85\%), carbohydrates (11.2\%), citric acid $(5-7 \%)$, protein $(1 \%)$, vitamin-C $(0.5 \%)$, fat $(0.9 \%)$, minerals $(0.3 \%)$, fibers $(1.6 \%)$ and some other organic acids. As lemon juice is acidic in nature $(\mathrm{pH} \approx 2-3)$ and percentage of citric acid (5-7\%) is more than other acids, it works as acid catalyst for Schiff bases formation [2].

\section{Experimental}

All the reagents required for the reaction were brought from Aldrich Chemicals and were chemically pure. The solvents were freshly distilled before use. The elemental analysis of carbon, hydrogen and nitrogen were performed at spectroscopy /analytical test facility, Indian institute of science. Infra-red spectra of complexes were recorded in $\mathrm{KBr}$ pellets with a Perkin - Elmer 597 spectrophotometer in the range 4000-400 cm-1. The 1H-NMR spectra were recorded in $\mathrm{CDCl}_{3}$ with Bruker $400 \mathrm{MHz}$ instrument using TMS as internal reference.

General method of the preparation of lemon juice: Lemon fruit was cut and squeezed to take the juice. The juice thus obtained was filtered and used for the reaction ( $1.0 \mathrm{ml}$ for each $0.500 \mathrm{~g}$ batch.) [2].

\section{Synthesis of ligands}

$\mathbf{P}(\mathrm{a})$ :To a stirring solution of 2-hydroxy-1-naphthaldehyde $(1.5 \mathrm{~g}, 9.1 \mathrm{mmol})$ lemon juice $1.0 \mathrm{ml}$ was added and continued

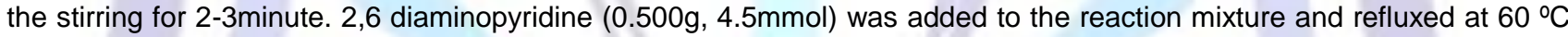
for $1.5 \mathrm{hrs}$. The reaction mixture was cooled to room temperature. The resulting precipitate was filtered and washed with cold ethanol. Reddish brown solid,78\% yield, purity was excellent after direct filtration of the reaction mixture

$\mathbf{P}(\mathbf{b})$ : To a stirring solution of 2-Methoxy-1-naphthaldehyde $(1.7 \mathrm{~g}, 9.1 \mathrm{mmol})$ lemon juice $1.0 \mathrm{ml}$ was added and continued the stirring for $2-3$ minute. 2,6 diaminopyridine $(0.500 \mathrm{~g}, 4.5 \mathrm{mmol})$ was added to the reaction mixture and refluxed at $60{ }^{\circ} \mathrm{C}$ for $1.5 \mathrm{hrs}$. The reaction mixture was cooled to room temperature. The resulting precipitate was filtered and washed with cold ethanol. Bright yellow solid, 73\% yield. Product obtained as recrystalized from ethanol.

$\mathrm{P}(\mathrm{c})$ : To a stirring solution of 1 -naphthaldehyde $(1.4 \mathrm{~g}, 9.1 \mathrm{mmol})$ lemon juice $1.0 \mathrm{ml}$ was added and continued the stirring for $2-3$ minute. 2,6 diaminopyridine $(0.500 \mathrm{~g}, 4.5 \mathrm{mmol})$ was added to the reaction mixture and refluxed at $60 \stackrel{\circ}{\circ}$ for $1.5 \mathrm{hrs}$. The reaction mixture was cooled to room temperature. The resulting precipitate was filtered and washed with cold ethanol.

Bright yellow solid, $60 \%$ yield, Product obtained as recrystalized from ethanol

\section{Conventional method:}

2, 6-diaminopyridine ( $4 \mathrm{mmol}, 0.436 \mathrm{gm}$ ) was added to a stirring solution of 2-hydroxy-1-

Napthaldehyde $(0.979 \mathrm{gm}, 8 \mathrm{mmol})$, prepared in methanol $(10 \mathrm{ml})$. The resulting mixture was refluxed at $60 \stackrel{\circ}{\circ}$ and stirred for $3 \mathrm{~h}$. The reaction mixture was cooled to room temperature and the resulting precipitate was filtered and washed with cold methanol. The brown residue was purified by column chromatography $(20 \%$ ethyl acetate/ $80 \%$ petroleum ether to give pure product [10]. Yield $\mathrm{P}(\mathrm{a})=68 \%, \mathrm{P}(\mathrm{b})=50 \%$ and $\mathrm{P}(\mathrm{c})=40 \%$ 


\section{Scheme 1}

\section{General mechanism for the formation of a Schiff base}<smiles>[R7]C=N[R7]</smiles>

\section{Scheme 2}

\section{Formation of Schiff base in presence of acid catalyst.}

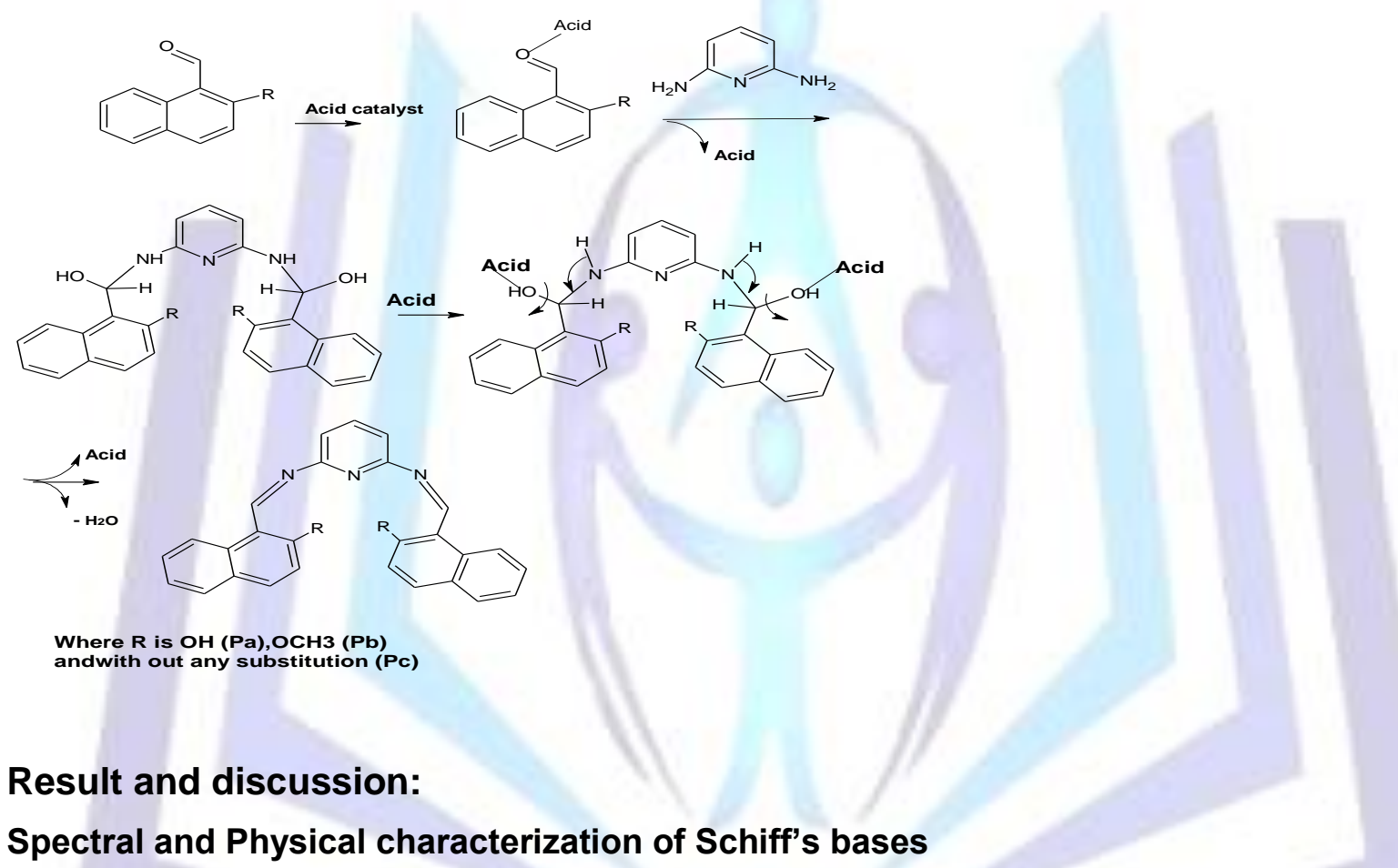

All compounds are stable and have sharp melting points that indicate the purity of the compounds. The elemental analysis is co operating with the compositions suggested for the compounds. The IR of each compound confirm the formation of the imide bond formation $(-\mathrm{C}=\mathrm{N})$ and the absence of the original aldehydes bond $(\mathrm{C}=\mathrm{O})$. Completion of reaction was also confirmed by treating the product with Schiff reagent, were the absence magenta colour indicated the absence of aldehyde.

P (a): Anal. Calc. for C27H19N3O2: Observed (Theoretical): C -76.7(77.69); H- 4.44(4.56); N-10.1(10.07); Infrared spectrum (cm-1 KBr disk); v(C=N) 1616, v (phenolic C-O) 1347; v (CH) 830,

1HNMR (CDCl3, ppm); (phenolic OH) $\delta$ 15.176-15.158 (d, 2H, OH exch.); $\delta 10.03$ (d, 2H, HC=N); $\delta$ 8.20-6.97(Ar-H) Coupling between protons from $\mathrm{OH}$ and $\mathrm{CH}=\mathrm{N}$ may be responsible for the doublets, LCMS: $(m+1)=418.1$

P (b): Infrared spectrum (cm-1 KBr disk); v(C=N) 1592, v (methoxy C-O) 1247, v (CH) 807

$1 \mathrm{HNMR}(\mathrm{CDCl} 3, \mathrm{ppm}): \delta 10.170(\mathrm{~s}, 1 \mathrm{H}, \mathrm{HC}=\mathrm{N}) ; \delta 8.351-7.258(\mathrm{Ar}-\mathrm{H}) ; \delta 4.059(\mathrm{~s}, 1 \mathrm{H}, \mathrm{OCH} 3)$ since there is no coupling is between $\mathrm{OCH} 3$ proton and $\mathrm{CH}=\mathrm{N}$ proton, singlet peak is observed for both the protons, $\mathrm{LCMS}:(\mathrm{m}+1)=447.2$

P (c): Infrared spectrum (cm-1 KBr disk); $\mathrm{v}(\mathrm{C}=\mathrm{N})$ 1578, $\mathrm{v}(\mathrm{CH}) 813$

1HNMR (CDCl3, ppm): $\delta 10.172(\mathrm{~s}, 1 \mathrm{H}, \mathrm{HC}=\mathrm{N}) ; \delta 8.352-7.260(\mathrm{Ar}-\mathrm{H})$ As there is no substituent to couple with $\mathrm{CH}=\mathrm{N}$ proton, again singlet is observed for $\mathrm{CH}=\mathrm{N}$ proton, LCMS: $(\mathrm{M}-1)$ Negative mode $=384.4$ 


\section{Biological Activity}

\section{Anti fungal and antibacterial studies}

All the compounds were evaluated for their antifungal activities with Aspergillus niger, M.fufur, orium, and antibacterial activity against E.coli, Klebsiella, Bacillus cereus, and Staphylococcus aureus by disc diffusion method.

Procedure: Sterilized Nutrient agar plates are prepared by autoclaving nutrient agar media and petri dishes at $121^{\circ} \mathrm{C}$ and $15 p s i$ for 15-20 minutes. Sterilized molten media is poured over petri dishes and allowed to solidify. Two Gram positive, Two gram negative bacteria and fungus culture of $100 \mu \mathrm{l}$ are spread over the solidified nutrient agar plates separately. Tetracycline discs were placed as control in bacterial plates and Forcan (fungal antibiotic $10 \mathrm{mg} / \mathrm{ml}$ ) were placed on fungal plates. $10 \mathrm{mg}$ of compounds $\mathrm{P}(\mathrm{a}), \mathrm{P}(\mathrm{b})$, and $\mathrm{P}(\mathrm{c})$ were dissolved in $1 \mathrm{ml}$ dimethylsulfoxide. $200 \mu \mathrm{l}$ of each extract was loaded into sterile filter paper discs and placed on the media. Plates were incubated at $37^{\circ} \mathrm{C}$ for 17 hours. After incubation the zone of inhibition formed on each plates were noted down $[15,16,17]$

\section{Result}

\begin{tabular}{|l|l|l|l|l|l|}
\hline & $\mathrm{Pa}$ & $\mathrm{Pb}$ & $\mathrm{Pc}$ & Forcan & Tetracycline \\
\hline E.coli & $10 \mathrm{~mm}$ & $\mathrm{R}$ & $\mathrm{R}$ & - & $30 \mathrm{~mm}$ \\
\hline Klebsiella & $11 \mathrm{~mm}$ & $\mathrm{R}$ & $\mathrm{R}$ & - & $\mathrm{R}$ \\
\hline Bacillus cereus & $11 \mathrm{~mm}$ & $\mathrm{R}$ & $\mathrm{R}$ & - & $23 \mathrm{~mm}$ \\
\hline $\begin{array}{l}\text { Staphylococcus } \\
\text { aureus }\end{array}$ & $10 \mathrm{~mm}$ & $\mathrm{R}$ & $\mathrm{R}$ & - & $15 \mathrm{~mm}$ \\
\hline $\begin{array}{l}\text { Aspergillus } \\
\text { niger }\end{array}$ & $\mathrm{R}$ & $\mathrm{R}$ & $\mathrm{R}$ & $1 \mathrm{~mm}$ & - \\
\hline M.fufur & $\mathrm{R}$ & $\mathrm{R}$ & $\mathrm{R}$ & $3 \mathrm{~mm}$ & - \\
\hline & & & & & \\
\hline
\end{tabular}

\section{R: Resistance}

In the present study, among all Schiff bases, $N, N^{\prime}$-bis (2-hydroxy-1-napthalene)-2,6-pyridiamine showed maximum inhibitory activity against all the bacteria. But it was resistant against Aspergillus niger and M.fufur.It is interesting to note that the same compound showed a significant inhibition compared to control sample tetracycline in case of Klebsiella,

Inhibition observed in each case is given,

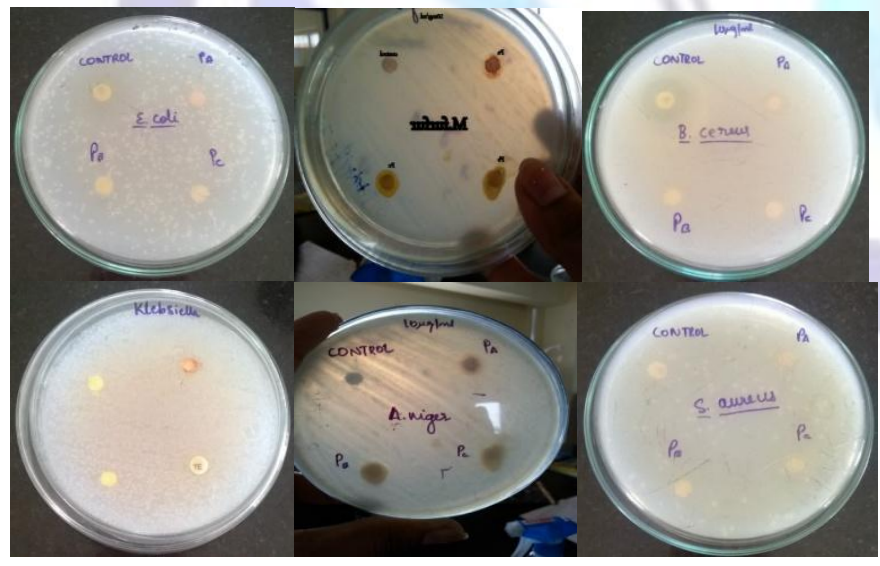

\section{Conclusion}

In this paper, we are reporting an efficient eco-friendly route for the synthesis of Schiff bases by using lemon Juice as the catalyst. The products are purified by recrystallization using appropriate solvents. Compared to traditional methods, this method gives good yield and reduces the time required for the reaction. It is cleaner, safer and more eco-friendly. The reaction also required mild reaction conditions and simple workup. Schiff bases thus prepared were characterized by using spectral methods and tested for microbial activities and some of them showed good inhibition as well. 


\section{Acknowledgement:}

Authors are thankful to Government Science College, Nrupatunga Road, Bangalore for providing the research facilities and to IISc Bangalore for the Spectral data. Devika Bhai R greatly acknowledges the support from The Oxford College of Science, Bangalore.

\section{Reference:}

1. Schiff bases: A Review on Biological Insights /P. Anand ${ }^{1}$, V.M. Patil ${ }^{1 *}$, V.K. Sharma ${ }^{1}$, R.L. Khosa ${ }^{1}$, N. Masand ${ }^{2} /$ International Journal of Drug Design and Discovery, Volume 3 • Issue 3 • July - September 2012. 851-868

2. Natural Acid Catalyzed Synthesis of Schiff Base under Solvent-free Condition: As a Green Approac Suresh Patil ${ }^{*}$, S. D. Jadhav and U. P. Patil / Arch. Appl. Sci. Res., 2012, 4 (2):1074-1078

3. Green Route for Efficient Synthesis of Novel Amino Acid Schiff Bases as Potent Antibacterial and Antifungal Agents and Evaluation of Cytotoxic Effects / Harshita Sachdeva,1 Rekha Saroj,1 Sarita Khaturia,1 Diksha Dwivedi,1 andOm Prakash Chauhan/ Journal of Chemistry Volume 2014 (2014), Article ID 848543, 12 pages http://dx.doi.org/10.1155/2014/848543 Research Article

4. The Mechanism of Hydrolysis of Schiff Bases Derived from Aliphatic Amines BYE. H. CORDESA ND K' P. JENCKS, received april 26, 1963.

5. Facile and efficient method for preparation of schiff bases catalyzed by $\mathrm{Ni}(\mathrm{NO} 3) 2.6 \mathrm{H} 2 \mathrm{O}$ under room temperature shrikrishna d. tupare, dinesh v. bhagat, satish a. dakea and rajendra p. pawar* Int. J. Chem. Sci.: 10(4), 2012, 18371843 ISSN 0972-768X Schiff Bases: A Short Survey on an Evergreen Chemistry Tool Wenling Qin 1, Sha Long 1, Mauro Panunzio 2, ${ }^{*}$ and Stefano Biondi 3,Molecules 2013, 18, 12264-12289; doi:10.3390/molecules181012264

6. Synthesis and photoluminescent properties of a Schiff-base ligand and its mononuclear $\mathrm{Zn}$ (II), $\mathrm{Cd}(\mathrm{II}), \mathrm{Cu}(\mathrm{II}), \mathrm{Ni}(\mathrm{II})$ and Pd(II) metal complexes/ E.S. Aazam a, ${ }^{\star}$, A.F. EL Husseiny b, H.M. Al-Amri Arabian Journal of Chemistry (2012) 5, 45-53

7. An overview of biological aspects of Schiff base metal complexes / Neelima Mishra, KavitanPoonia and Dinesh Kumar' - International Journal of Advancements in Research \& Technology, Volume 2, Issue 8, August-2013 52 ISSN 2278-7763 Copyright @ 2013 SciResPub. IJOART

8. ISSN: 2249-0337 Original Article Eco-friendly synthesis Of Schiff bases/ Rahim ullah shaikh, Nida s. shaikh, Dipak T.tayade/ International Journal of Pharmacy and Pharmaceutical Science Research 2013; 3(3): 100-102

9. Synthesis, Characterization and $\mathrm{Pb}$ (II) lon Selectivity of $N, N^{\prime}$ - bis(2-hydroxy-1-napthalene)-2,6-pyridiamine (BHNPD) V.K. Gupta*, A.K. Jain and Gaurav Maheshwari/ Int. J Electrochem. Sci., Vol. 2, 2007

10. Schiff Bases: A Short Survey on an Evergreen Chemistry Tool Wenling Qin 1, Sha Long 1, Mauro Panunzio 2, ${ }^{*}$ and Stefano Biondi $3,{ }^{*}$ Molecules 2013, 18, 12264-12289; doi:10.3390/molecules181012264

11. Synthesis, Characterization and Biological activity of Chiral Schiff Bas/ Internationale Pharmaceutica Sciencia| October-December 2013 | Vol. 3 | Issue 4 |Available online http://www.ipharmsciencia.comISSN 2231-5896 @2013 IPS

12. Chemistry and Biological Importance of Heterocyclic Schiff's Bases Mithun Rudrapal ${ }^{1 *}$ and Biplab De ${ }^{2 /}$ International Research Journal of Pure \& Applied Chemistry 3(3): 232-249, 2013 Science domain international/ www.sciencedomain.org

13. Synthesis and DNA binding studies of novel heterocyclic substituted Quinoline Schiff bases: A potent antimicrobial agent Devappa. S. Lamani, ${ }^{1}$ Kallam. R. Venugopala Reddy, ${ }^{1}$ H. S.

Bhojya Naik, A. Savyasachi, ${ }^{1}$ and H. Raja. Naik ${ }^{2}$ / Nucleosides, Nucleotides and Nucleic

Acids, 27:1197-1210, 2008

14. Synthesis and Evaluation of Schiff's base of 4-quinazolinone analogues as Antimicrobial agents Shweta tiwari* ${ }^{* 1}$ Vikas mujalda ${ }^{1}$, Vasudha sharma ${ }^{1}$, Pushplata saxena ${ }^{1}$, Manjul Shrivastava ${ }^{2} /$ Asian Journal of Pharmaceutical and Clinical Research Vol 5, Issue 1, 2012 ISSN - 0974-2441

Synthesis, spectral characterization and antimicrobial screening of novel schiff bases from sulfa drugs Gomathi Vellaiswamy* and Selvameena Ramaswam/ International Journal of Pharmacy and Pharmaceutical Sciences, ISSN0975-1491 Vol 6, Issue 1, 2014

15. Synthesis of substituted schiff's bases and their antimicrobial activity P. B. Raghuwanshi*and P.V.Mahalle**/Department of Chemistry, Brijlal Biyani Mahavidyalaya, Amravati(M.S.), India/DerPharmaChemica, 2014, 6(1):262-266 (http://derpharmachemica.com/archive.html) 


\section{Author' biography}

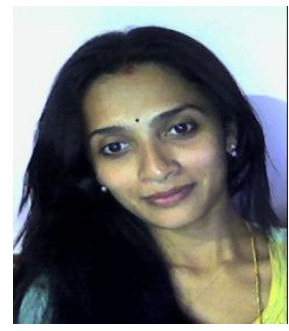

Devika Bhai $R$ was born in Kerala, India in 1981. She received her B.Sc. (2002) from MG University, Kerala, India; M.Sc. (2004) from Kuvempu University, Karnataka, India; currently pursuing PhD under Bharathiar University, TamilNadu, India. At present, she is Assistant Professor in the Chemistry Department, The Oxford Science College, Bangalore, India. Apart from three years of experience in teaching, she has five years of research experience from Syngene International Ltd, an internationally reputed research and manufacturing organization. 